\title{
Cavitation Simulation of Automotive Torque Converter Using a Homogeneous Cavitation Model
}

\author{
Keisuke Tsutsumi ${ }^{1}$, Satoshi Watanabe ${ }^{2}$, Shin-ichi Tsuda ${ }^{3}$ and Takeshi Yamaguchi ${ }^{4}$
}

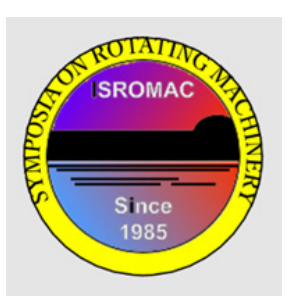

ISROMAC 2016

International

Symposium on Transport

Phenomena and

Dynamics of

Rotating Machinery

Hawaii, Honolulu

April 10-15, 2016

\begin{abstract}
To understand the flow mechanism of cavitation and its effect on the performance of automotive torque converter, numerical simulation considering cavitation is carried out at various turbine-pump speed ratios from 0 to 0.8 . Since the cavitation in working fluid of torque converter is rather gaseous than vaporous, the partial pressure of air is applied to the cavity pressure in the simplified Rayleigh Plesset cavitation model used in the present simulations. It is found that, for the lower speed ratios $(<0.4)$, the cavitation starts to occur firstly at the stator with the decrease of the ambient pressure, which seems to significantly block the stator passage. The mass flow circulating in the torque converter gradually decreases, which results in the gradual decrease of the pump torque. On the other hand, for the higher speed ratios (>0.6), the cavitation occurs at the pump inlet simultaneously or earlier than that at the stator. Once the cavitation occurs at the pump, the pump torque seems to drop suddenly.

\section{Keywords}

Torque converter — Gaseous cavitation — Numerical analysis — Rayleigh-Plesset model

\footnotetext{
${ }^{1}$ Graduate School of Engineering, Kyushu University, Fukuoka, Japan

${ }^{3}$ Department of Mechanical Engineering, Kyushu University, Fukuoka, Japan

${ }^{4}$ AISIN AW Co Ltd., Anjo, Japan

*Corresponding author: fmnabe@mech.kyushu-u.ac.jp
}

${ }^{2}$ Department of Mechanical Engineering, Kyushu University, Fukuoka, Japan
\end{abstract}

\section{INTRODUCTION}

The hydraulic torque converter is one of the key components of automatic transmission, which transfers the power from the engine to the gear system. It consists of two rotating elements, mixed flow pump and turbine, and one stationary element, axial stator. The pump element is directly driven by the internal combustion engine, which gives the angular momentum to the automatic transmission fluid (ATF). The turbine element collects the angular momentum of the fluid and transfer the torque to the gear system. The stator element leads the exiting flow from the turbine to the pump inlet, giving the additional angular momentum to the fluid especially at low turbine to pump speed ratios. As a result, the torque converter can multiply the torque from pump to turbine elements at low speed ratios, which enables automobiles to start with poor low speed torque characteristics of internal combustion engine.

Because of more densely packaged engine room of recent well-designed automobiles, the torque converter is being required to be more compact with flattened toroidal shape, which leads to more susceptibility of cavitation. Since the cavitation causes not only the erosion and the deteriorations of static and dynamic performances of torque converter but also the noises and vibrations, even a very small amount of bubble generations, i.e. cavitation inception, should be avoided. Nevertheless, many studies of hydraulic torque converter have been devoted to understand the complicated but only single-phase flow structure both experimentally ([1]-[4]) and numerically ([5]-[6]), and there have been made few reports on cavitation in it. Among them, Robinette et al. ([7], [8]) have proposed an indirect detection method of cavitation from emitted noises. Watanabe et al. [9] firstly conducted the naked-eye visualization of cavitation using a fully transparent model of whole three elements of typical type of torque converter. Although the visualization was carried out only at the stall condition with zero turbine speed, they have reported that the cavitation occurs firstly in the vortical structures around the stator element and then in the flow-separated region on the suction side of stator blades, which triggers the deterioration of the torque performance. However, the flow mechanism of cavitation and its relation to the performance of torque converter have not yet fully understood and should be clarified in the wide range of operating speed ratios.

In the present study, the numerical simulation of cavitation using a commercial computational fluid dynamics (CFD) code ANSYS-CFX is carried out at various speed ratios, to understand the static characteristics of torque converter against cavitation.

\section{NUMERICAL SIMULATION}

\subsection{Numerical model}

Figure 1 shows the analytical model of hydraulic torque converter used in the present study. The model torque converter is the same one used in our experimental study [9]. The numbers of blades in pump, turbine and stator elements are 31, 29 and 20 respectively, but only one flow passage of the each element is considered in the present simulation to reduce the computational cost. Therefore, each domain containing the pump, turbine and stator is connected via socalled stage interface, at which the circumferential averaged flow variables are conserved among two domains, therefore only the steady simulation is available and is carried out here. The non-slip wall condition is applied for the all solid walls. The flow inside the torque converter is basically a closed 
toroidal flow, while a part of shell wall is removed to set the base pressure there for cavitation simulation, which is similar to the experimental condition [9]; the opening boundary condition with the specified static pressure $p_{\infty}$ is applied. The total number of nodes contained in this model is around $1,090 \mathrm{k}$, and many nodes among them are distributed in the stator domain since the working condition of the stator varies more remarkably against the various speed ratio. The turbulence model used is $k-\omega$ based SST model. The rotational speed of the pump element is set to be constant with $N_{p}=800 \mathrm{~min}^{-1}$ and the speed ratios of turbine to pump $e$ is varied as $e=0,0.2,0.4,0.6$ and 0.8 .

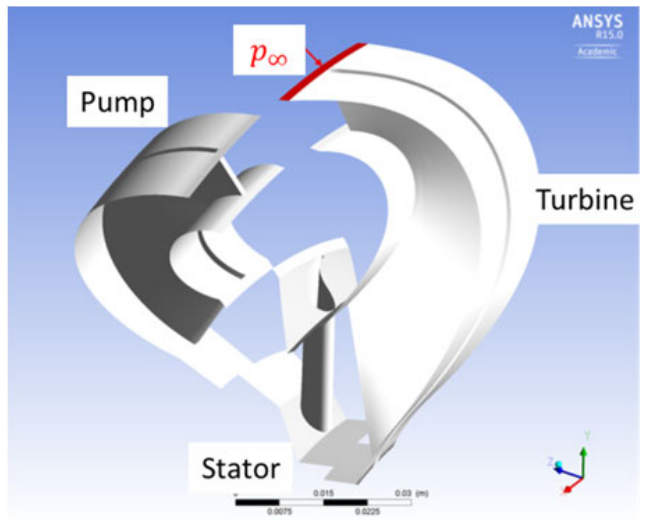

Fig.1 Analytical model

\subsection{Cavitation model}

In the present simulation, cavitation simulation using the homogeneous cavitation model implemented in ANSYSCFX-15 is carried out, in which the following mass conservation equation of gas phase is solved in addition to the usual set of RANS (Reynolds Averaged Navier-Stokes) equations.

$$
\frac{\partial \rho_{g} \alpha}{\partial t}+\frac{\partial}{\partial x_{j}}\left(\rho_{g} \alpha u_{j}\right)=\dot{m}^{+}+\dot{m}^{-}
$$

where $\rho_{g}$ and $\alpha$ respectively denote the density and volume fraction of gas phase (latter called void fraction), and $u_{j}$ is a velocity component in $x_{j}$ direction.

Source terms $\dot{m}^{+}$and $\dot{m}^{-}$in the above equation express the mass production and destruction of the gas phase. In the present study, so-called Rayleigh Plesset Model, that is one of the famous homogeneous cavitation model, is applied despite the gaseous nature of cavitation in the real machine. The production and destruction terms for this model are as follows.

$$
\begin{gathered}
\dot{m}^{+}=F^{+} \frac{3 \alpha \rho_{g}}{R_{n u c}} \sqrt{\frac{2}{3} \frac{\left(p_{c}-p\right)}{\rho_{l}}}\left(p<p_{c}\right) \\
\dot{m}^{-}=-F^{-} \frac{3 \alpha_{n u c}(1-\alpha) \rho_{g}}{R_{n u c}} \sqrt{\frac{2}{3} \frac{\left(p-p_{c}\right)}{\rho_{l}}} \quad\left(p>p_{c}\right)
\end{gathered}
$$

where the coefficients $F^{+}$and $F^{-}$, the radius of bubble nuclei $R_{n u c}$ and the volume fraction of bubble nuclei $\alpha_{n u c}$ are the model constants, and the default values, $F^{+}=50, F^{-}=0.01$ $R_{n u c}=1 \mu \mathrm{m}$ and $\alpha_{n u c}=5 \times 10^{-4}$ are used throughout this study. The both production and destruction of gas phases are driven by the square-root of pressure difference between local pressure $p$ and the bubble wall pressure $p_{c}$ divided by the liquid density $\rho_{l}$; the value of $p_{c}$ in the gaseous cavitation of the working fluid ATF (automatic transmission fluid) is determined in the following way.

The working fluid ATF is known to contain large amount of air in the dissolved form. The vapor pressure is very small compared with that of water at room temperature. Therefore, the cavitation occurring in the torque converter is rather gaseous than vaporous. In gaseous cavitation, it is appropriate to solve the mass transfer of gas dissolved in the liquid to determine the cavity pressure $p_{c}$ which is used for the above mentioned simplified Rayleigh-Plesset model. However, in the present study, for simpler simulation, it is assumed that the diffusion of the dissolved air in the liquid is sufficiently fast because the flow inside the torque converter is highly turbulent, and employ the simplified Rayleigh-Plesset model with the cavity pressure $p_{c}$ assumed to be a constant gas pressure $p_{g}$.

It is basically difficult to determine the gas partial pressure inside the cavity. If the gas-liquid two phases co-exist at the quiescent condition, the gas pressure may be determined by the Henry's law as $p_{g}=H Y$, where $H$ and $Y$ are respectively the Herny's constant and the mass fraction of dissolved air in the liquid phase. However, since the flow inside the torque converter is very complicated and far from that in the quiescent condition, we multiply the coefficient $\kappa$ to the gas pressure as follows.

$$
p_{g}=\kappa H Y
$$

where $\kappa$ takes some value between 0 and 1. The Henry's constant of ATF fluid is unknown, but the value of $H Y$ is determined to be $30 \%$ of atomspheric pressure, which is identical to that in the dearation condition in our previous experiment [9].

Although the cavitation observed in torque converter is gaseous, it is still convenient to define the cavitation number used for vaporous cavitation, since we have no information on real gas pressure in the bubbles in experiments. The cavitation number $\sigma$ is defined as follows by using the peripheral speed of pump element $U$ as a reference velocity.

$$
\sigma=\frac{p_{\infty}-p_{v}}{\rho U^{2} / 2} \approx \frac{p_{\infty}}{\rho U^{2} / 2}
$$

where $p_{\infty}$ is the specified static pressure at the opening boundary shown in Fig. 1.

\section{Results and discussions}

\subsection{Hydraulic performances of torque converter}

Figure 2 shows the torque characteristic curves of torque converter elements obtained by the present CFD and the experiment (EXP). $K_{1}=T_{p} / N_{p}{ }^{2}$ and $K_{2}=T_{t} / N_{p}{ }^{2}$ plotted against the speed ratio $e$ are the torque capacity coefficients of the pump and turbine elements respectively, where $T_{p}$ is a torque added to the pump element, $T_{t}$ a torque generated by the turbine element, and $N_{p}\left[\mathrm{~min}^{-1}\right]$ the rotational speed of pump element. The all torque coefficients are normalized by the pump torque at the speed ratio of $e=0.8$ near the maximum efficiency point $K_{1 b e p}$ obtained by the experiment. The experimental data are not obtained by our experiment but are given by the manufacturer. Both the CFD and the experiment have been carried out at a non-cavitating condition. 
We can clearly see the good agreement between the present CFD and the experiment over the wide range of the speed ratio.

Although the present CFD is the simple steady simulation using single passage for the all pump, turbine and stator elements, this fact encourages us to conduct the cavitation CFD for the present investigation.

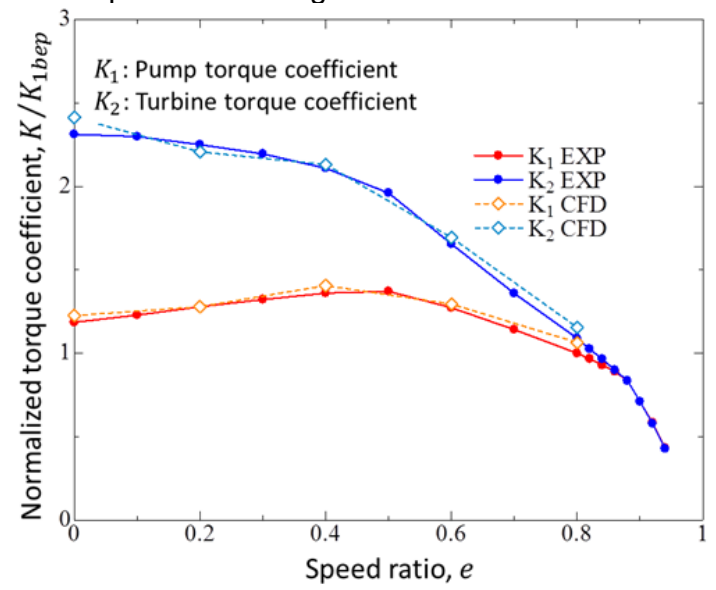

Fig.2 Comparisons of torque characteristics of pump and turbine elements between present CFD and experiment

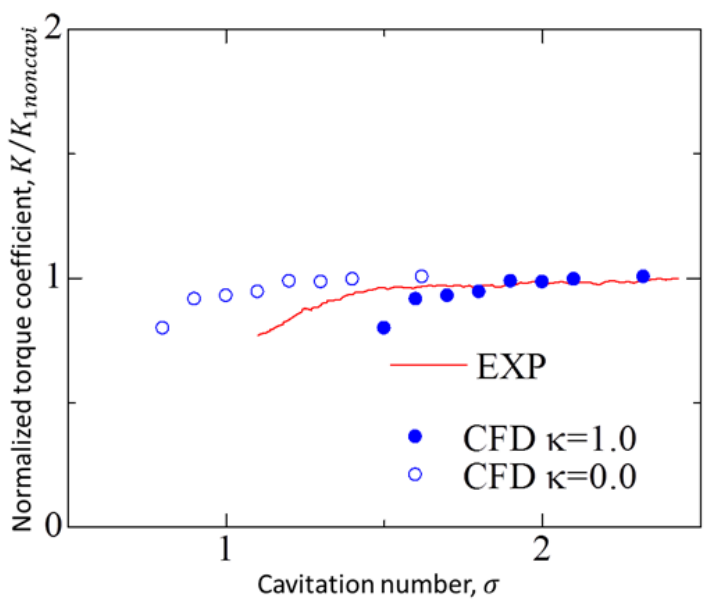

Fig.3 Comparison of torque performance of pump element against cavitation at stall condition $(e=0)$ between CFD and experiment [9]

\subsection{Cavitation characteristics}

Figure 3 shows the suction performance of pump element at the stall condition, that is the condition with the speed ratio of $e=0$. The torque coefficient has been normalized by that of the pump at non-cavitating condition. In the present CFD, two extreme values of the coefficient, $\kappa=0$ (no air in cavitation bubbles) and 1.0 (saturated air in bubbles), are assumed. In addition to the results of CFD the experimental result [9] is also plotted for the comparison. It is clearly seen that, for the both CFD and experiment, the pump torque gradually decreases with the decrease of the cavitation number $\sigma$, i.e. the development of cavitation. The shapes of the curves obtained by the present CFD and the experiment are very similar, and the suction performance curve obtained by the experiment locates between two cases of CFD. This fact indicates that the some amount of air actually forms the bubbles.
Figure 4 shows the appearance of cavitation at roughly $5 \%$ drop of the pump drop obtained by (a) CFD ( $\sigma=1.8, \kappa=1.0)$ and (b) experiment $(\sigma=1.35)$ [9]. In the CFD result, cavitation is visualized by the iso-surface of $10 \%$ void fraction. Cavitation can be seen only around the stator blade for the both CFD and experiment, which means that the performance drop is caused by cavitation in the stator blade at the stall condition with $e=0$.

Those results may suggest us that, given the appropriate values of the partial pressure of air in the cavitation bubbles $p_{c}$, it would be possible to predict the suction performance of torque converter by the simple cavitation model. However, since we are not focusing on the accurate prediction of the performance but on understanding the mechanism of performance drop with the development of cavitation, the cavitation CFD is carried out with assuming the air saturated gaseous cavitation with $\kappa=1.0$. The assessment of the partial gas pressure in the cavitation bubbles is left for our future study.

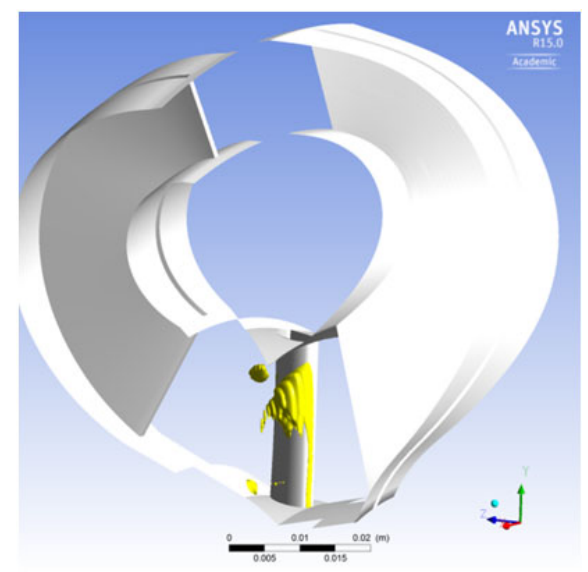

(a) Iso-surface of $10 \%$ void fraction at $\sigma=1.8(\kappa=1.0)$

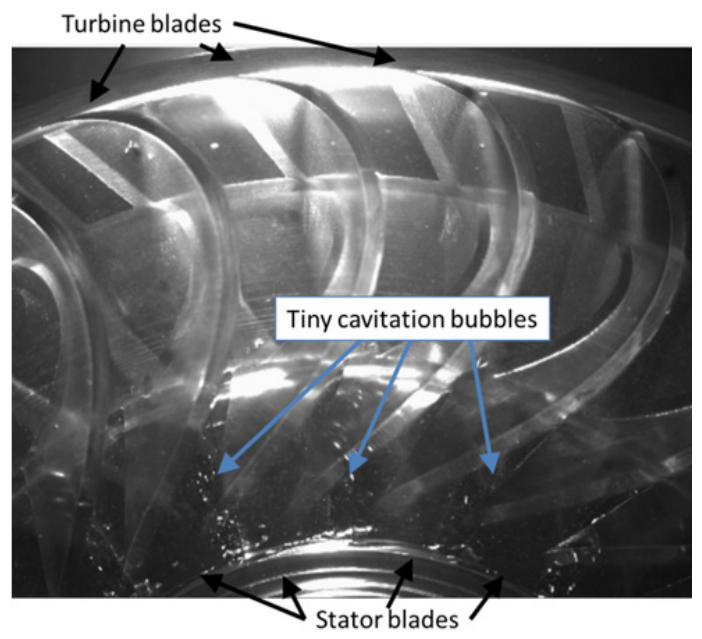

(b) Experiment at $\sigma=1.35$

Fig.4 Comparisons of appearance of cavitation at torque drop between CFD and experiment [9] $(e=0)$

\subsection{Effect of speed ratio on pressure distribution}

It is noticeable in Fig. 2 that the stator torque increases almost linearly with the decrease of the speed ratio $e$ while the pump torque has a flat characteristics against the speed ratio. Therefore, it is thought that the pressure distribution around the stator drastically changes with the change of the speed 
ratio, and the appearance of the cavitation also changes. Actually, Fig. 5 shows the pressure distribution on the suction sides of the pump and stator blades at the speed ratios of (a) $e=0.2$ and (b) $e=0.8$ obtained by the present CFD in non-cavitating condition. The absolute pressure normalized by the dynamic pressure of the pump peripheral speed $U$ is plotted in the figures. At $e=0.2$, we can clearly recognize the low pressure region from the leading edge of the stator blade, and we expect that the cavitation occurs mainly in the stator element as similar to that at the stall condition with $e=0$ (Fig.4). On the other hand, at $e=0.8$ where the stator torque is small, the low pressure region in the stator element moves downstream on the suction surface, and the low pressure region appears near the leading edge of the pump blade. Therefore, at the larger speed ratios, the cavitation is expected to occur not only in the stator but also in the pump element. In the next two sub-sections, the mechanism of the torque drop against the cavitation is investigated by the present CFD separately for the lower and higher speed ratios.

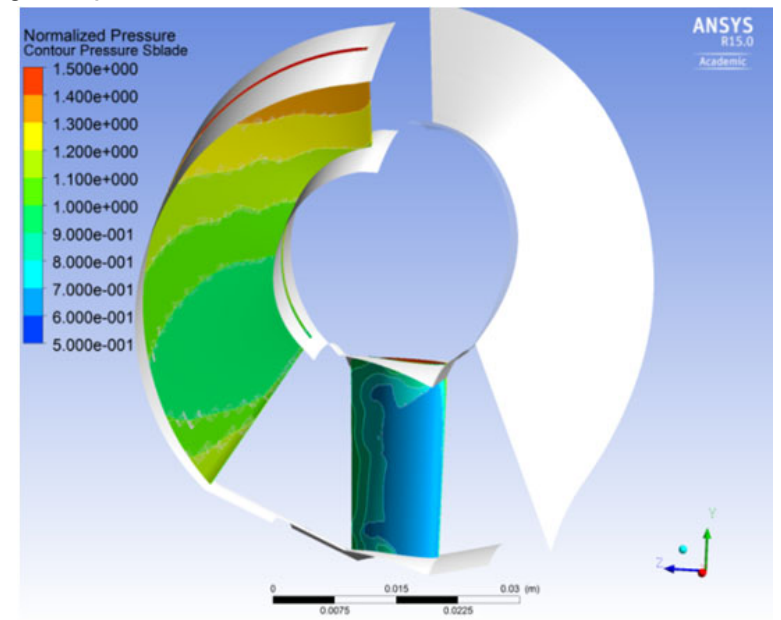

(a) $e=0.2, \sigma=2.32$

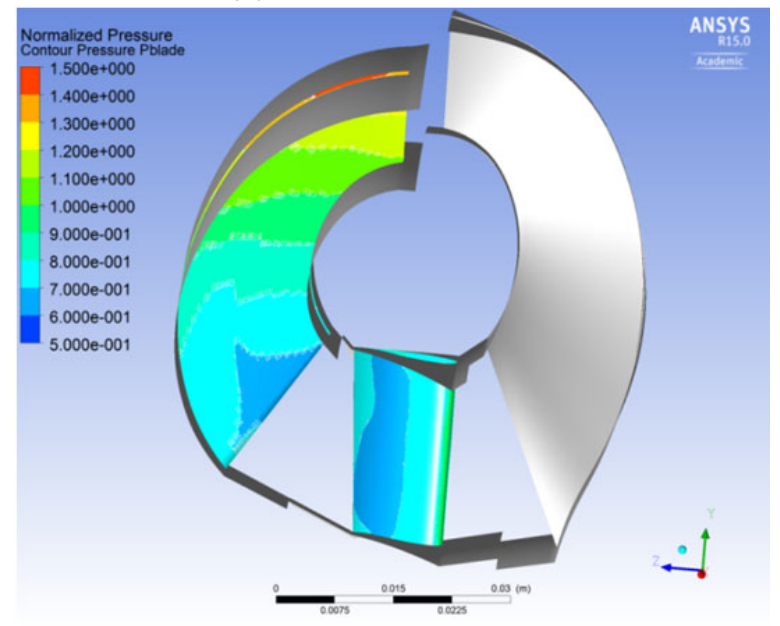

(b) $e=0.8, \sigma=2.32$

Fig.5 Pressure distribution on suction surfaces of stator and pump blades in non-cavitating condition

\subsection{Low speed ratio $(e=0.0,0.2,0.4)$}

Figure 6 shows the pump, turbine and stator torques plotted against the cavitation number at the speed ratios of (a) $e=0$, (b) $e=0.2$ and (c) $e=0.4$. All pump, turbine, stator torques are normalized by that of the pump in the non-cavitating condition. In those conditions, it can be clearly seen that the turbine torque is well increased by the stator, and the torque decrease characteritics against the cavitation number is similar; as the cavitation number decreases, the all pump, turbine and stator torques gradualy decreases.

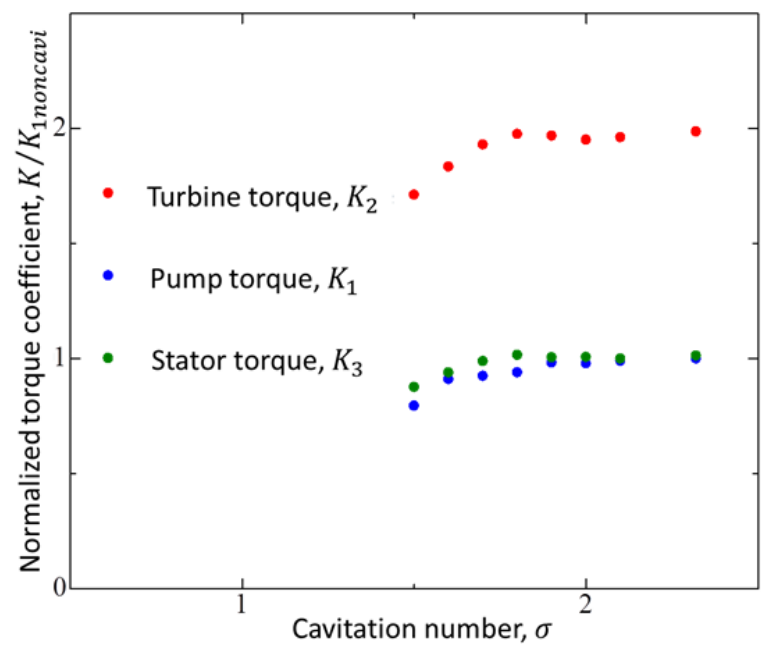

(a) $e=0$

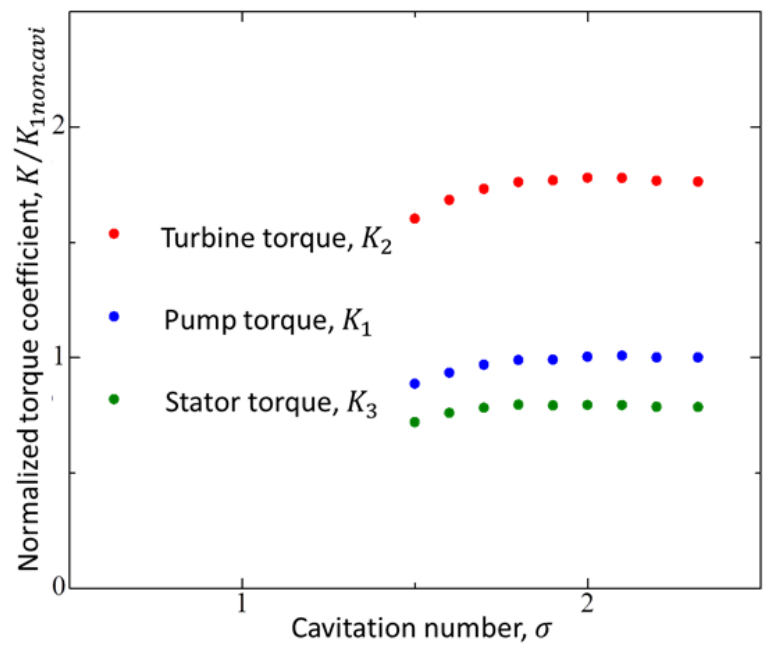

(b) $e=0.2$

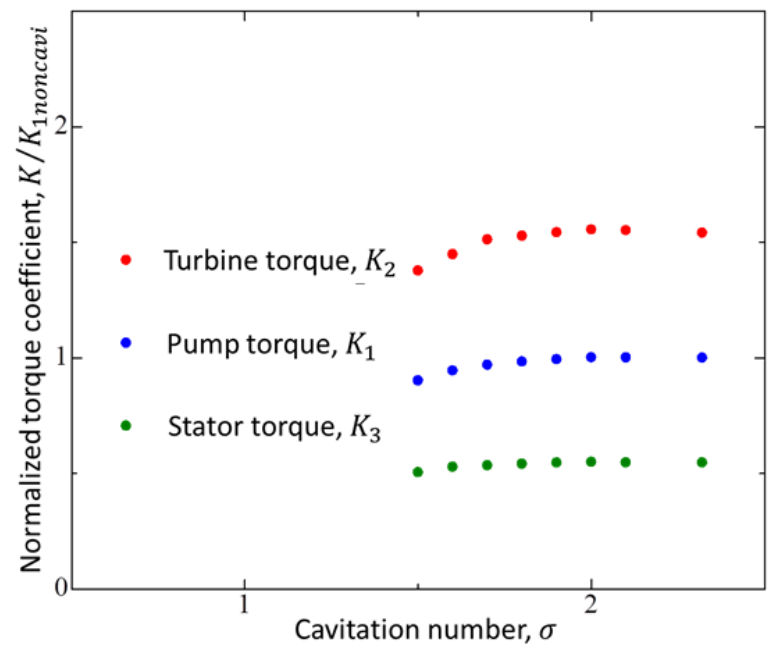

(c) $e=0.4$

Fig. 6 Torque performance of pump, turbine and stator elements against cavitation at low speed ratios 


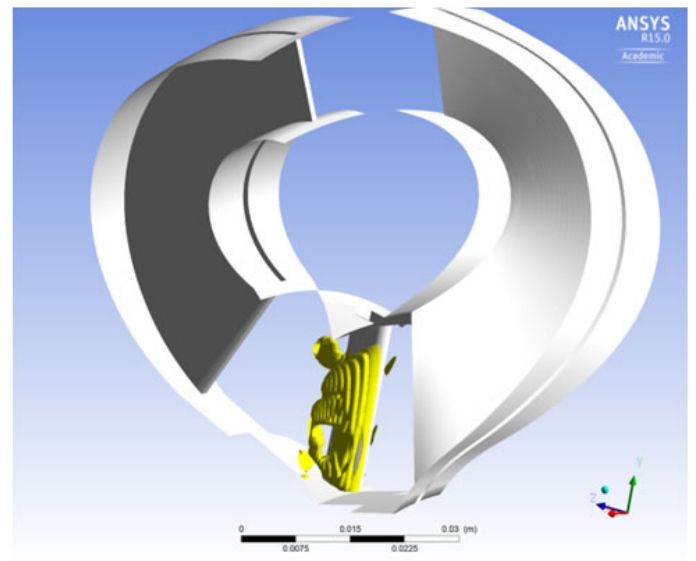

(a) $e=0, \sigma=1.70$

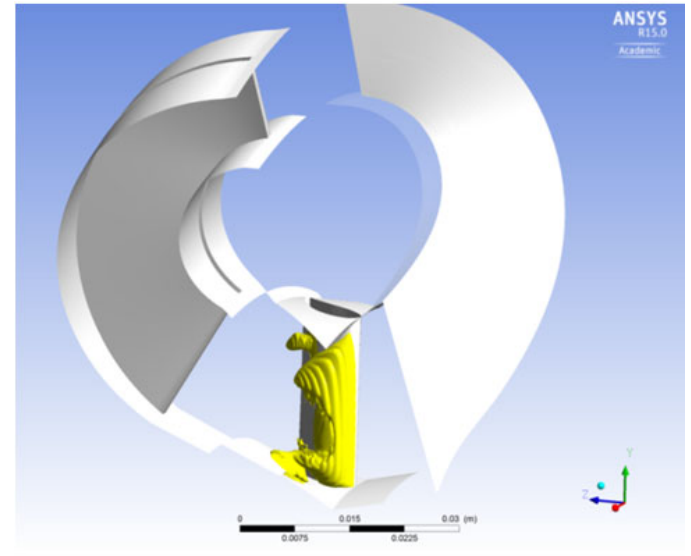

(b) $e=0.2, \sigma=1.55$

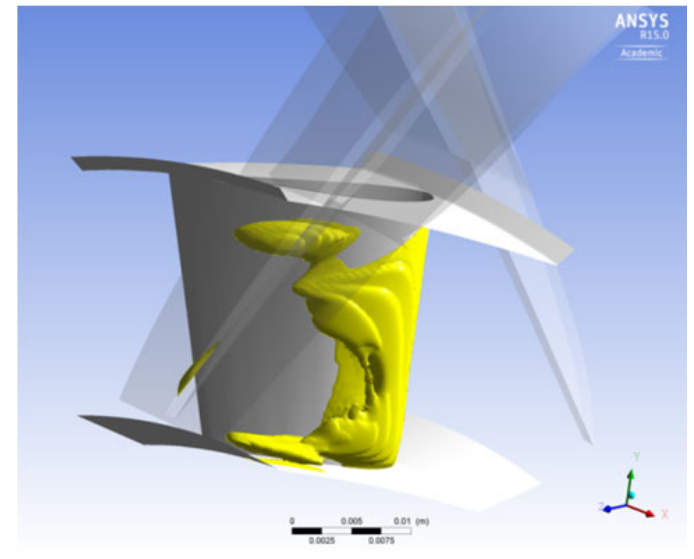

(c) $e=0.4, \sigma=1.50$

Fig.7 Appearance of cavitation with $10 \%$ decrease of pump torque from non-cavitating torque

Figure 7 shows the apperacne of cavitation at the cavitation number with roughly $10 \%$ decrease of the pump torque from non-cavitating condition for the speed ratios of (a) $e=0(\sigma=1.7)$, (b) $e=0.2(\sigma=1.6)$ and (c) $e=0.4$ $(\sigma=1.5)$. Cavitation is visualized by the iso-surface of $10 \%$ void fraction. In the all cases, cavitation can be seen only around the suction surface of the stator blade. Therefore, the stator cavitation is the cause of the gradual performance degradation at the low speed ratios. According to the present CFD simulation, it was found that the toroidal mass flow rate in this condition was decreased about $5 \%$ of that in the non- cavitation condition. Therefore, the reason for the pump, turbine and stator torque decreases at the low speed ratio is the decrease of the toroidal flow rate due to the increase of the resistance at the stator through the development of cavitation.

\subsection{High speed ratio $(e=0.6,0.8)$}

Figure 8 shows the pump, turbine and stator torques plotted against the cavitation number $\sigma$ at the speed ratio of $e=0.6$. All pump, turbine, stator torques are normalized by that of the pump in the non-cavitating condition. As the cavitation number decreases, the turbine and stator torque decrease monotonously. On the other hand, the pump torque slightly decreases at $\sigma=1.50$, but it recovers at $\sigma=1.40$. Figure 9 shows the iso-surface of $10 \%$ void fraction at $\sigma=1.50$. The cavitation can be seen only at the stator element, which is similar to the lower speed ratio conditions with $e=0-0.2$. Therefore, the slight decrease of the torque at $\sigma=1.50$ is caused by the similar reason for $e=0-0.2$. On the other hand, as shown in Fig. 10, in which the appearance of cavitation around (a) the stator and (b) pump regions are presented, it is clearly seen that the cavitation occurs not only in the stator but also along the core surface of the pump element. Therefore, the change of the meridional flow pattern in the pump element with the decrease of the cavitation number to $\sigma=1.50$ is thought to cause the recovery of the pump torque at this cavitation number.

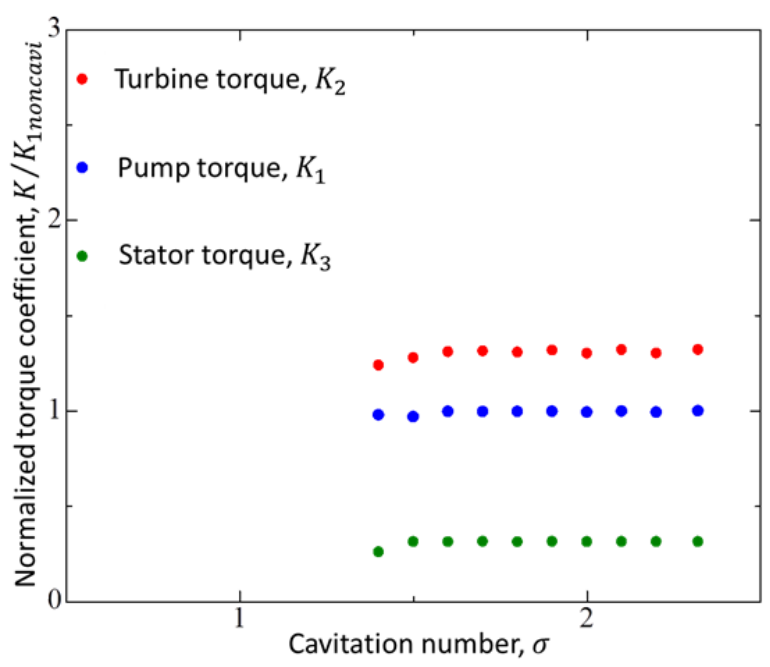

Fig. 8 Torque performance of pump, turbine and stator elements against cavitation at $e=0.6$

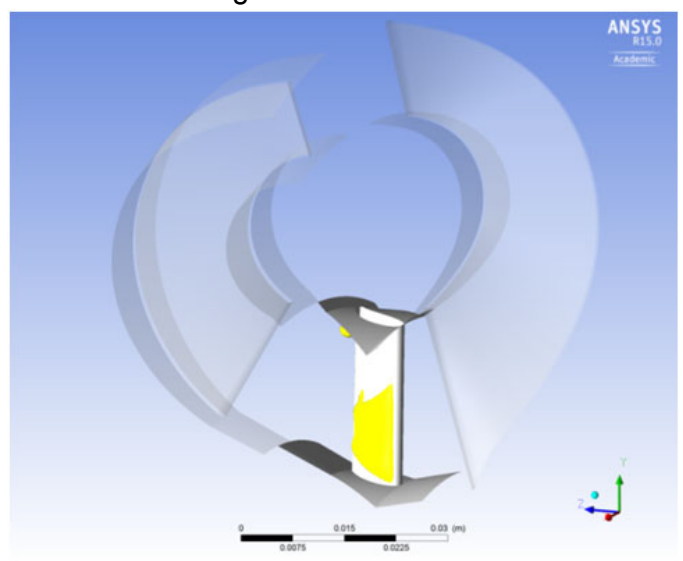

Fig.9 Appearance of cavitation at $e=0.6, \sigma=1.50$ 
Actually, Fig. 11 shows the circumferentially averaged meridional velocity distribution at (a) $\sigma=2.32$ (non-cavitating condition), (b) $\sigma=1.50$ and (c) $\sigma=1.40$. The velocity shown here has been normalized by the pump peripheral velocity $U$. In these figures, it is difficult to recognize the difference between $\sigma=2.32$ and $\sigma=1.50$, whereas the meridional velocity is seen to be more higher near the outer surface (shell side) in aft-part of the pump element at $\sigma=1.40$, therefore the exiting flow from the pump element is thought to be more distorted at this condition. Fig. 12 shows the comparisons of the radial distributions of circumferentially averaged angular momentum flux at (a) inlet and (b) outlet surfaces of the pump element domain. Note that the angular momentum flux can be directly related with the torque through the conservation law of angular momentum. At the inlet, the angular momentum flux distribution is almost unchanged with the decrease of the cavitation number. However, due to the blockage effect of cavitation along the core surface in the pump element, the angular momentum flux distribution significantly changes from $\sigma=1.50$ to $\sigma=1.40$. This is the flow mechanism which leads the recovery of the pump torque at this cavitation number.

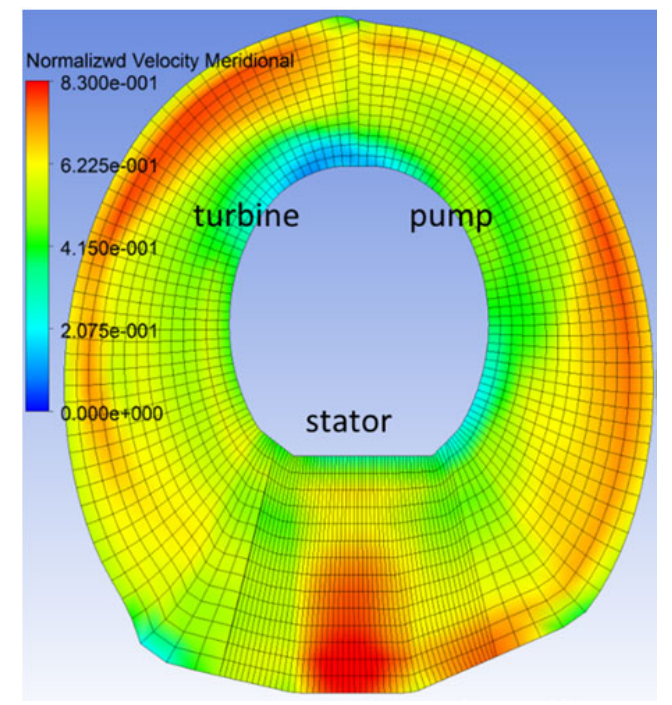

(a) $\sigma=2.32$

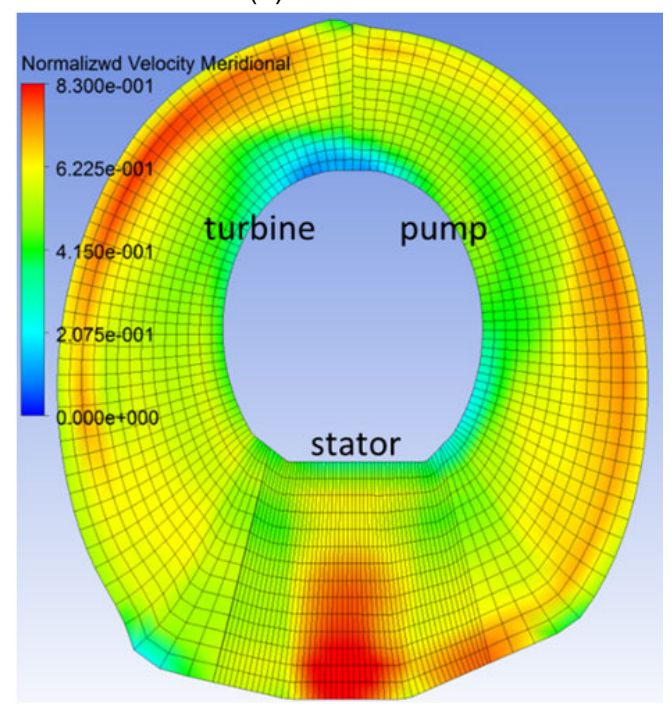

(b) $\sigma=1.50$

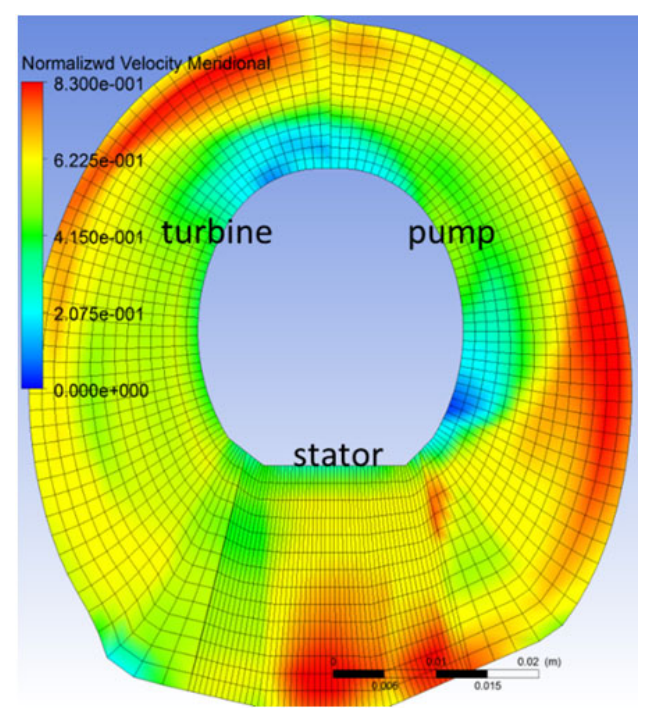

(c) $\sigma=1.40$

Fig.11 Circumferentially averaged meridional velocity distributions at speed ratio of $e=0.6$

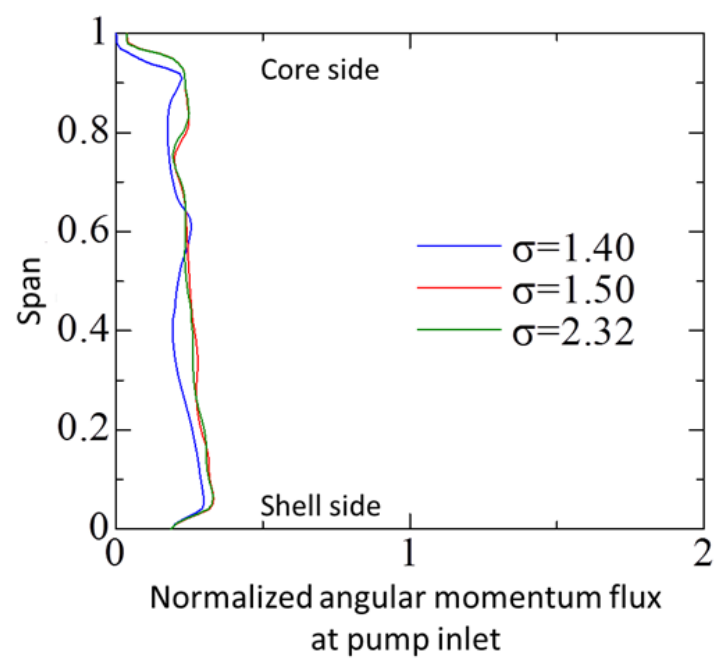

(a) Inlet

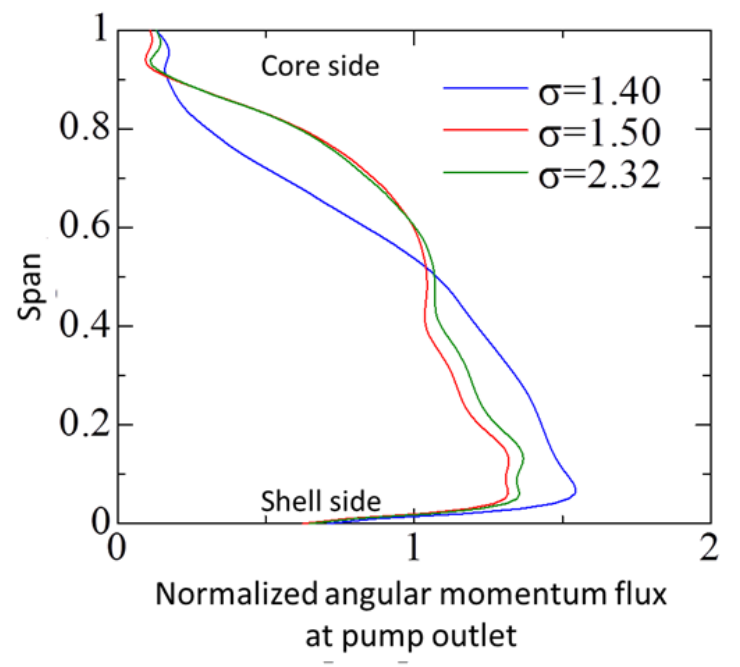

(b) Outlet

Fig.12 Circumferentially averaged angular momentum flux at inlet and outlet surfaces of pump domain $(e=0.6)$ 
Even with the slight decrease of the cavitation number from $\sigma=1.40$, the present simulation never converged. This fact may imply that the sudden torque drop occurs with this cavitation number, which results in unstable torque balance among the three elements.

Figure 13 shows the pump, turbine and stator torques plotted against the cavitation number $\sigma$ at the speed ratio of $e=0.8$. All pump, turbine, stator torques are normalized by that of the pump in the non-cavitating condition. At this speed ratio, it can be seen that the torques of all elements keep almost constant with the decrease of the cavitation number to $\sigma=1.40$. After that, they apparently decrease with the very small decrease of cavitation number. Figure 14 shows the appearance of cavitation. From Fig.14 the substantial development of cavitation can be seen on the suction side of the pump blade. The cavitation around the pump blades seems to be responsible for the sudden drop of torque converter elements at the higher speed ratios.

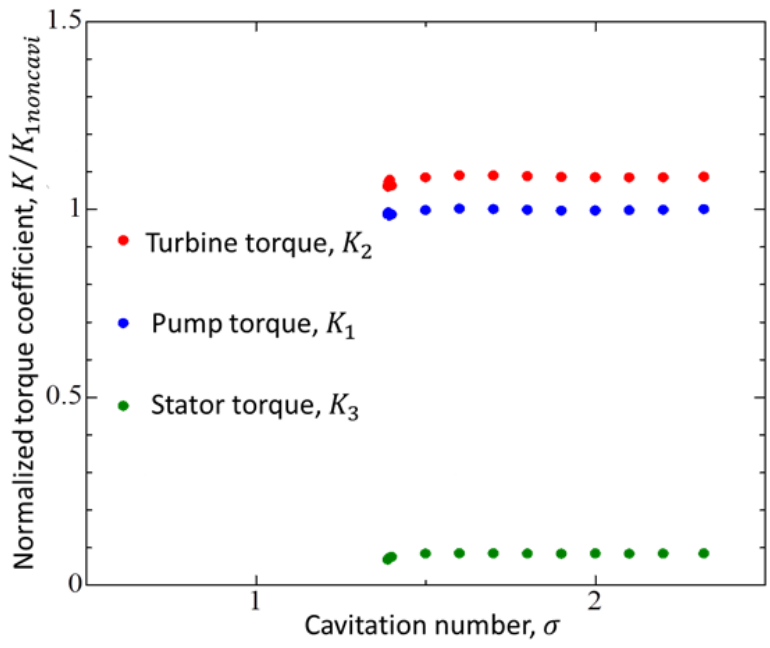

Fig.13 Torque performance of pump, turbine and stator elements against cavitation at $e=0.8$

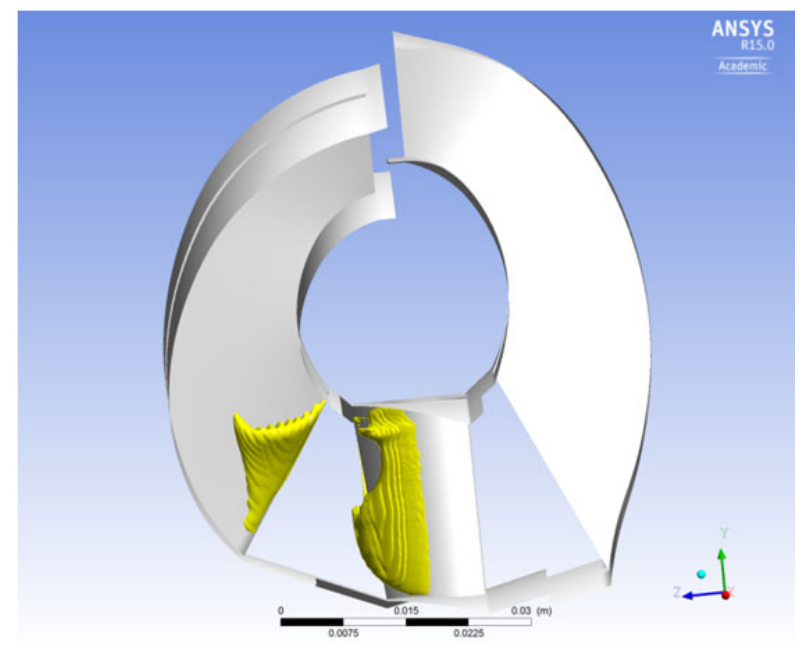

Fig.14 Appearance of cavitation at $e=0.8, \sigma=1.40$

\section{Conclusion}

To clarify the relationship between the torque converter performances and the development of cavitation, cavitation CFD using a simple homogeneous cavitation model has been carried out. The assumed partial pressure of air in the cavitation bubbles are used in the bubble wall pressure in the simplified Rayleigh-Plesset model. Main conclusions are summarized as follows.

(1) The present CFD with assumed gas pressure inside bubbles can qualitatively reproduce the torque characteristics of pump element against cavitation at the stalled condition. This may suggest that, given the accurate value of the gas pressure, the present CFD would well predict the cavitation performance of torque converter.

(2) At lower speed ratios, since the blade loading of the stator is high, cavitation remarkably occurs around the suction surfaces of stator blades. The blockage effect of stator cavitation is more pronounced with the decrease of the cavitation, which seems to be responsible for the gradual degradation of the torque characteristics of torque converter against cavitation.

(3) At higher speed ratios, the blade loading of the stator is less, and the cavitation occurs around the pump blades as well as around the stator blades with the decrease of cavitation number. Once the pump cavitation occurs, the torque performance of all torque converter elements is deteriorated with the small decrease of the cavitation number. Therefore, it can be said that the pump cavitation is responsible for the sudden drop of torque converter performance at higher speed ratios.

\section{References}

[1] Y. Dong and B. Lakshminarayana. Rotating Probe Measurements of the Pump Passage Flow Field in an Automotive Torque Converter, ASME J. Fluids Eng., Vol. 123, pp. 81-91, 2001.

[2] Y. F. Liu, B. Lakshminarayana and J. Burningham. Flow Field in the Turbine Rotor Passage in an Automotive Torque Converter Based on the High Frequency Response Rotating Five-Hole Probe Measurement: Part I: Flow Field at the Design Condition (Speed Ratio 0.6), Int. J. Rotating Machinery, Vol. 7, pp. 253-269, 2001.

[3] Y. F. Liu, B. Lakshminarayana and J. Burningham. Flow Field in the Turbine Rotor Passage in an Automotive Torque Converter Based on the High Frequency Response Rotating Five-Hole Probe Measurement: Part II: Flow Field at OffDesign Condition and Effects of Speed Ratio, Int. J. Rotating Machinery, Vol. 7, pp. 271-284, 2001.

[4] K. O. Kraus, R. Flack, A. Habsieger, G. T. Gillies and K. Dullenkopf. Periodic Velocity Measurements in a Wide and Large Radius Ratio Automotive Torque Converter at the Pump/Turbine Interface, ASME J. Fluid Eng., Vol. 127, pp. 308-316, 2005.

[5] R. R. By, R. Kunz and B. Lakshminarayana. Navier-Stokes Analysis of the Pump Flow Field of an Automotive Torque Converter, J. Fluids Eng., Vol. 117, pp. 116-122, 1995.

[6] C. Liu, A. Untaroiu, H. G. Wood, Q.-D. Yan and W. Wei. 
Parametric Analysis and Optimization of Inlet Deflection Angle in Torque Converter, ASME J. Fluid Eng., Vol. 137, pp. 031101, 2015.

[7] D. L. Robinette, J. M. Schweitzer, D. G. Maddock, C. L. Anderson, J. R. Blough and M. A. Johnson. Predicting the Onset of Cavitation in Automotive Torque Converters-Part I: Designs with Geometric Similitude," Int. J. Rotating Machinery, Vol. 2008, Article ID 803940, 2008.

[8] D. L. Robinette, J. M. Schweitzer, D. G. Maddock, C. L. Anderson, J. R. Blough and M. A. Johnson. Predicting the Onset of Cavitation in Automotive Torque Converters- Part II: A Generalized Model, Int. J. Rotating Machinery, Vol. 2008, Article ID 312753, 2008.

[9] S. Watanabe, R. Otani, S. Kunimoto, Y. Hara, A. Furukawa and T. Yamaguchi. Vibration Characteristics due to Cvitation in Sator Element of Automotive Torque Converter at Stall Condition, Proc. ASME Fluids Eng. Div. Summer Meeting, FEDSM2012-72418, 2012. 